\title{
Changes in fucosylation of human seminal IgG and secretory component of IgA in leukocytospermic patients
}

\author{
Ewa M. Kratz • Miroslawa Ferens-Sieczkowska • \\ Ricardo Faundez • Iwona Kątnik-Prastowska
}

Received: 2 July 2013 /Revised: 21 August 2013 / Accepted: 2 September 2013 /Published online: 22 September 2013

(C) The Author(s) 2013. This article is published with open access at Springerlink.com

\begin{abstract}
Our study compares the status of human seminal plasma immunoglobulin $\mathrm{G}(\mathrm{IgG})$ and $\mathrm{IgA}$ secretory component (SC) fucosylation between infertile leukocytospermic and normal, fertile normozoospermic patients. The seminal IgG and $\mathrm{SC}$ are decorated with AAL-reactive core fucose, and antennary UEA- and LTA-reactive fucose of Lewis ${ }^{y}$ and Lewis ${ }^{\mathrm{x}}$ structures, respectively. However, a correlation between $\operatorname{IgG}$ core fucosylation and $\operatorname{IgG}$ concentration $(r=-0.52$; $p<0.0003$ ) was observed. The IgG present in leukocytospermic samples is characterized by lower expression of core fucose than in the normal group $(0.82 \pm 0.3 \mathrm{AU}$ and $1.2 \pm 0.3 \mathrm{AU}$, respectively; $p<0.002$ ). In seminal plasma the $\mathrm{SC}$ is present in two forms: $78-\mathrm{kDa}$ and $63-\mathrm{kDa}$. The present study has also shown a higher AAL and LTA specific reactivity of glycans expressed in $63-\mathrm{kDa} \mathrm{SC}$, in comparison to $78-\mathrm{kDa} \mathrm{SC}$, in the normal group. In leukocytospermia, the values of specific lectin reactivity for core fucose, fucose $\alpha(1-2)$ - and $\alpha(1-3)$ - linked, were similar for both SC bands. Moreover, the present study has shown that in leukocytospermic samples the mean concentrations of $\operatorname{IgG}$ and S-IgA are twice as high $(131.68 \pm 102.6 \mathrm{mg} / \mathrm{l}$ and $36 \pm 27 \mathrm{mg} / \mathrm{l}$, respectively) as in the normal group (67.68 \pm $29.2 \mathrm{mg} / 1 ; p<0.02$, and $19 \pm 18 \mathrm{mg} / 1, p<0.019$, respectively). The analysis of IgG and SC fucosylation status and the determination of IgG and S-IgA concentrations in seminal plasma
\end{abstract}

E. M. Kratz $(\bowtie) \cdot$ M. Ferens-Sieczkowska $\cdot$ I. Kątnik-Prastowska Department of Chemistry and Immunochemistry, Wrocław Medical University, Bujwida 44a, 50-345 Wrocław, Poland

e-mail: ewa.kratz@umed.wroc.pl

R. Faundez

Embryology Laboratory InviMed - European Center of Motherhood, Rakowiecka 36, 02-532 Warsaw, Poland

R. Faundez

Department of Large Animal Diseases and Clinic Division of Animal Reproduction, Andrology and Biotechnology of Reproduction, Warsaw University of Life Sciences Faculty of Veterinary Medicine, Nowoursynowska 100, 02-797 Warsaw, Poland might constitute a valuable diagnosis tools for the evaluation of male infertility associated with leukocytospermia with accompanying inflammation.

Keywords Immunoglobulin $\mathrm{G} \cdot$ Secretory component . Fucosylation $\cdot$ Leukocytospermia $\cdot$ Male infertility

\section{Introduction}

From an immunological point of view, seminal plasma is designed to protect male sperm cells against infection and to inhibit the immune response against sperm cells in both male and female reproductive organs. Seminal plasma has inhibitory properties due to the presence of biologically active factors, such as enzymes, steroids, hormones, proteins, cytokines and immunoglobulins, mainly $\mathrm{G}(\operatorname{IgG})$ and $\mathrm{A}(\operatorname{Ig} \mathrm{A})$.

Physiologically, normal human ejaculate does not contain more than $1 \times 10^{6} / \mathrm{ml}$ of leukocytes, but in leukocytospermia the number of leukocytes exceeds this value [1]. Leukocytes play an important role in the immune "supervision" [2] and removal of abnormal sperm cells by phagocytosis [3]. The increased number of leukocytes in semen indicates urogenital tract infection and inflammation [4]. Adversely, leukocytes are a source of oxidative stress [5] and thus lower the quality of male gametes [6]. Leukocytospermia is frequently observed in 10-20\% of subfertile and 10-44\% of infertile men [7, 8]. Yilmaz et al. [9] showed that the amount of sperm and number of sperm cells with fast progressive movement in leukocytospermic men is two times lower than those observed in patients without leukocytospermia with abnormal sperm parameters.

Immunoglobulin $\mathrm{G}$, the most abundant immunoglobulin in blood plasma, is involved in the recognition, neutralization and elimination of pathogens and toxic antigens. Glycans attached to blood plasma IgG molecules may differ in the content of fucose, galactose, sialic acid and presence or absence of bisecting $N$-acetylglucosamine [10]. An important role is 
attributed to the presence of core fucose $\alpha(1-6)$ - linked on Nglycans of $\operatorname{IgG}$ [11]: its absence causes a 50 -fold increase in antibody binding to the Fc $\gamma$ RIIIA present on natural killer cells [12], thus increasing antibody or complement-mediated cellular cytotoxicity [13]. Little is known about the profile of human seminal plasma $\mathrm{IgG}$ fucosylation.

Secretory immunoglobulin A (S-IgA), accounts for two thirds of antibodies found on mucosal surfaces and is present in colostrum, tears, sweat, gastrointestinal secretions, respiratory and urogenital tracts $[14,15]$. Secretory $\operatorname{IgA}$ prevents microorganisms and other antigens from penetrating the surface of the mucous membranes. It is also responsible for neutralization of viruses and enhances non-specific defence mechanisms [16]. Glycans of S-IgA form additional binding sites for bacteria and may participate in both the innate and acquired immunity [17]. The most important feature of S-IgA is the presence of a secretory component (SC) [18], which is a glycoprotein of $50-90 \mathrm{kDa}$ [14]. The secretory component is synthesized by epithelial cells of the digestive system, respiratory and urogenital tracts. SC may be attached to immunoglobulin A or M, and/or may exist in free form in secretions. The secretory module gives S-IgA structural stability and increases its resistance to proteolytic digestion during transportation through the epithelium to the mucous-serous secretions [19]. Secretory component contains 5-7 N-linked oligosaccharides, which constitute about $22 \%$ of its total molecular mass [20]. Royle et al. [17] in their studies on human colostrum S-IgA, showed that most of the oligosaccharide structures expressed on human SC are bi-antennary. Tri- and tetra-antennary glycans are less abundant $(11.7 \%$ and $<1 \%$, respectively). All the glycans contain galactose, but not bisecting GlcNAc [17]. Most N-glycans (70 \%) expressed on SC contain sialic acid, and over $65 \%$ of the glycans contain core fucose. Some of the oligosaccharide antennas may also be fucosylated. The secretory molecule may express each of the known structures of Lewis- and/or sialyl-Lewis-types, which are responsible for specific binding of bacterial adhesins [17].

Our previous study [21] showed that seminal S-IgA concentration is not associated with sperm parameters. Immunoblotting analysis has shown that seminal SC is present in two forms, with molecular masses around $80-$ and $60-\mathrm{kDa}$ [21]. In the present study we investigated the differences in fucosylation of seminal $\operatorname{IgG}$ and $\operatorname{IgA}$ secretory component forms and their association with leukocytospermia of infertile males.

\section{Materials and methods}

\section{Specimens}

Human ejaculates were collected from fertile donors (2645 years old) and leukocytospermic infertile patients (age matched to the normal group). The ejaculates were collected by masturbation into sterile containers after $3-5$ days of sexual abstinence, and were allowed to stand at $37{ }^{\circ} \mathrm{C}$ until liquefaction (no longer than $1 \mathrm{~h}$ ). Next, standard semen analysis (volume, $\mathrm{pH}$, morphology, sperm concentration, motility, and viability) was done at the Warsaw InviMed semen analysis laboratory according to WHO criteria [1]. Semen samples were centrifuged at $3500 \times \mathrm{g}$ for $10 \mathrm{~min}$ at room temperature to obtain plasma. Seminal plasma was divided into small aliquots and frozen at $-76{ }^{\circ} \mathrm{C}$ until use. Ejaculates were collected according to ethical standards (Ethical Committee approval KB-216/2011).

Seminal plasma samples were divided into two groups: normal $(n=17)$ and leukocytospermic $(n=28)$. In the normal group, the count of spermatozoa was higher than $15 \times 10^{6} / \mathrm{ml}$ and more than $4 \%$ expressed the correct sperm morphology with a total motility of $\geq 40 \%$ or progressive motility $\geq 32 \%$ at $1 \mathrm{~h}$ after ejaculation. The leukocytospermic group was formed from samples in which the leukocyte number was higher than $1 \times 10^{6} / \mathrm{ml}$ according to WHO criteria [1]. None of the leukocytospermic samples were normozoospermic.

\section{$\operatorname{IgG}$ and $\mathrm{S}-\operatorname{Ig} \mathrm{A}$ concentration}

Immunoglobulin $\mathrm{G}$ concentration was determined by radial immunodiffusion [22] using goat anti-human IgG polyclonal antibodies (BIOMED, Warsaw, Poland) and Human Serum Protein Calibrator (DakoCytomation, Denmark) as a standard. The concentration of S-IgA was determined by sandwich ELISA, using mouse monoclonal antibody directed against human SC of IgA (1:20,000; Sigma Chemical Co., St. Louis, MO, USA) and preparation of IgA from human colostrum (Sigma Chemical Co., St. Louis, MO, USA) as a standard. Rabbit anti-human IgA polyclonal antibodies (1:100,000; DakoCytomation, Denmark) were used to quantify the amount of seminal S-IgA bound by the capture antibody. Goat anti-rabbit IgG-HRP (1:10,000; Sigma Chemical Co., St. Louis, MO, USA) was used as a detection antibody. $O$-phenylenediamine dihydrochloride activated with $\mathrm{H}_{2} \mathrm{O}_{2}$ was used as the enzyme substrate. Colorimetric reaction was subsequently stopped with $12.5 \% \mathrm{H}_{2} \mathrm{SO}_{4}$. The colour intensity was measured in a Stat Fax 2100 Microplate Reader (Awareness Technology Inc., Palm City, FL, USA) at $492 \mathrm{~nm}$ using a reference filter at $630 \mathrm{~nm}$. All ELISA immunobinding reactions and washing steps were carried out in $10 \mathrm{mM}$ Trisbuffered saline (TBS) containing $0.05 \%$ Tween 20, pH 7.5, and the blocking step in the presence of $0.1 \%$ BSA (Sigma Chemical Co., St. Louis, MO, USA). Background absorbance (lower than $0.1 \mathrm{AU}$ ) was measured for TBS containing $0.05 \%$ Tween 20, pH 7.5 instead of a seminal plasma sample, but with all other reagents. Seminal plasmas with known concentrations of S-IgA were used as positive controls. All samples were analysed in duplicate. 
Determination of IgG fucose exposure by lectin-ELISA

Three biotinylated fucose-specific lectins (Vector Laboratories Inc., Burlingame, CA, USA): Aleuria aurantia lectin (AAL), Ulex europaeus agglutinin (UEA) and Lotus tetragonolobus agglutinin (LTA) were used to determine expression of fucose moiety in IgG by lectin-ELISA according to the procedure described previously for fibronectin and $\alpha_{1}$-acid glycoprotein [23]. The lectins differ with respect to their reactivity with differently bound terminal sugars on glycoproteins. The Aleuria aurantia lectin reacts mainly with the innermost fucose $\alpha(1-6)$ - linked to $N$-acetylglucosamine core of $\mathrm{N}$-glycans and with lower affinity with fucoses $\alpha(1-2)-, \alpha(1-3)$ - and $\alpha(1-4)$ linked of the outer arms [24]. Ulex europaeus agglutinin is specific to antennary fucoses $\alpha 1,2$-linked to Gal and $\alpha 1,3$ linked to GlcNAc, typical for Lewis ${ }^{\mathrm{y}}$ glycan structures [25]. The presence of fucose $\alpha 1,2$-linked prevents the formation of sialyl-Lewis ${ }^{\mathrm{x}}$ oligosaccharide structures [26]. Lotus tetragonolobus agglutinin specifically reacts with fucose $\alpha 1,3-$ linked to GlcNAc, characteristic for Lewis ${ }^{\mathrm{x}}$ structures, however, it can also slightly react with fucose typical for Lewis ${ }^{\mathrm{a}}$ and Lewis ${ }^{y}$ oligosaccharide structures. The presence of terminal sialic acid $\alpha(2-3)$ - linked in glycoprotein glycan structures limits the recognition of fucose $\alpha(1-3)$ - linked by LTA [27].

\section{Removal of terminal sugars from capture antibodies}

Monoclonal anti-human IgG antibodies had to be defucosylated before use in lectin-ELISA to avoid the lectin binding to capture antibodies. We have previously described the IgG defucosylation procedure [23]. Briefly, one volume of polyclonal goat anti-human $\mathrm{IgG}$ antibodies $(200 \mu \mathrm{l}, \mathrm{pH}=8.1)$ was mixed with an equal volume of $100 \mathrm{mmol} / 1 \mathrm{NaIO}_{4}$ in $100 \mathrm{mmol} / 1 \mathrm{NaHCO}_{3}, 0.2 \%$ Tween $20, \mathrm{pH}$ 8.1. The mixture was incubated for $90 \mathrm{~min}$. at room temperature in the dark and subsequently dialysed against $100 \mathrm{mmol} / 1 \mathrm{NaHCO}_{3}, \mathrm{pH} 9.2$, for $3 \mathrm{~h}$ at $4{ }^{\circ} \mathrm{C}$. Such treatment resulted in elimination of antibody reactivity with fucose-specific lectins.

\section{Lectin-ELISA procedure}

Expression of exposed fucosyl-residues of glycoproteins was determined by fucose-specific lectins AAL, UEA and LTA, as described earlier [23]. Defucosylated polyclonal goat antihuman IgG antibodies (BIOMED, Warsaw, Poland) were diluted in $10 \mathrm{mM}$ TBS pH $8.5(1: 10,000)$, coupled to a polystyrene microtiter ELISA plate and incubated for $2 \mathrm{~h}$ at $37{ }^{\circ} \mathrm{C}$. Seminal plasma samples were diluted in $10 \mathrm{mM}$ TBS, $1 \mathrm{mM}$ $\mathrm{CaCl}_{2}, 1 \mathrm{mM} \mathrm{MgCl}_{2}, 0.05 \%$ Tween 20 , and $0.5 \%$ glycerol, $\mathrm{pH} 7.5$, to obtain a glycoprotein solution containing $100 \mathrm{ng}$ of IgG in $100 \mu$ l. Upon addition of seminal plasma samples, plates were incubated for $2 \mathrm{~h}$ at $37^{\circ} \mathrm{C}$. All samples were analysed in duplicate. Background absorbance was measured for samples in which all reagents were present, but seminal plasma was replaced with a $10 \mathrm{mM}$ TBS, $1 \mathrm{mM} \mathrm{CaCl} 2,1 \mathrm{mM} \mathrm{MgCl}_{2}$, $0.05 \%$ Tween 20 , and $0.5 \%$ glycerol, $\mathrm{pH} 7.5$. To control for the specificity of lectin-glycoprotein interaction and to check the absence of detectable endogenous reactive materials, control probes were included for the test. Haptoglobin and asialohaptoglobin preparations derived from ovarian cancer fluid were used as positive controls [28], whereas a human albumin preparation served as negative control (Sigma Chemical Co., St. Louis, MO, USA). The $\alpha(1-6)-, \alpha(1-3)$ - and $\alpha(1-2)$ - linked fucose residues in $\mathrm{IgG}$ were detected by biotinylated AAL, LTA and UEA, respectively. Lectin dilutions (1:7500, 1:100 and 1:250, respectively) were established in preliminary experiments. All lectins were diluted in $10 \mathrm{mM}$ TBS containing $1 \mathrm{mM} \mathrm{CaCl}_{2}, 1 \mathrm{mM} \mathrm{MgCl} 2,0.05 \%$ Tween 20 , and $0.5 \%$ glycerine, $\mathrm{pH} 7.5$, and the plate was incubated for $1 \mathrm{~h}$ at $37^{\circ} \mathrm{C}$. The formed complex of IgG-biotinylated lectin was quantitated using phosphatase-labelled ExtrAvidin $\left(1 \mathrm{~h}\right.$ at $37^{\circ} \mathrm{C} ; 1: 20,000$; Sigma Chemical Co., St. Louis, MO, USA) and detected by the reaction with di-sodium 4-nitrophenyl phosphate (Merck, Darmstadt, Germany). The results were expressed in absorbance units (AU) measured at $405 \mathrm{~nm}$ with a reference filter of $630 \mathrm{~nm}$ in ELISA Stat Fax 2100 Microplate Reader (Awareness Technology Inc., Palm City, FL, USA). To remove any excess protein, the plate was washed three times with $10 \mathrm{mM}$ TBS, $0.05 \%$ Tween $20, \mathrm{pH}=7.5$ between each ELISA-step. The background absorbance values were not higher than $0.2 \mathrm{AU}$.

\section{Determination of SC bands by immunoblotting}

To determine the most characteristic immunoblot pattern for $\mathrm{SC}$ in leukocytospermic and normal seminal groups, equal volumes of samples in each seminal group were pooled. Next, the samples were diluted with $0.06 \mathrm{M}$ Tris $-\mathrm{HCl}, \mathrm{pH}=6.8$ containing $3 \%$ SDS (w/v), $10 \%$ glycerol (v/v) and $7.5 \%$ 2-mercaptoethanol $(\mathrm{v} / \mathrm{v})$, and boiled at $100{ }^{\circ} \mathrm{C}$ for $5 \mathrm{~min}$. Then 250 ng of S-IgA, determined by ELISA (for details see S-IgA concentration determination) was subjected to SDSpolyacrylamide gel electrophoresis on a $10 \%$ gel according to Laemmli [29] in a BioRad-vertical system (BioRad, Richmond, CA, USA). The separated proteins were subsequently blotted onto nitrocellulose (Serva Electrophoresis $\mathrm{GmbH}$, Heidelberg, Germany). After blocking (3\% powdered skim milk in $50 \mathrm{mM}$ TBS, pH 7.5), the blots were incubated with mouse monoclonal antibodies anti-human SC of IgA diluted at 1:1000 in $3 \%$ powdered skim milk in $50 \mathrm{mM}$ TBS, $\mathrm{pH} 7.5$, and probed with goat anti-mouse IgG polyclonal antibodies conjugated with horseradish peroxidase (1:2000 dilution in $3 \%$ powdered skim milk dissolved in $50 \mathrm{mM}$ TBS; Sigma Chemical Co., St. Louis, MO, USA). The colour reaction was developed with diaminobenzidine and $\mathrm{H}_{2} \mathrm{O}_{2}$. After each step, the nitrocellulose was washed at least 3 times 
using $50 \mathrm{mM}$ TBS, $0.05 \%$ Tween; $\mathrm{pH}=7.5$. Finally, the blots were dried and analysed. The blots were digitised and bands corresponding to secretory component of IgA (SC) were analysed with densitometry ImageJ $1.42 \mathrm{q}$ gel analysis software (National Institutes of Health, U.S. Department of Health \& Human Services public domain). The relative amounts of particular SC bands were expressed as the percentage of the total number of pixels in a lane. To calculate the molecular masses of SC bands, low molecular-weight protein mass standard (97.4-6.5 kDa; Serva Electrophoresis GmbH, Heidelberg, Germany) and human colostrum S-IgA preparation (Sigma Chemical Co., St. Louis, MO, USA) were used.

Lectin-blotting determination of secretory component fucose expression

The relative reactivity of SC bands was analysed in lectinblotting with biotinylated fucose-specific lectins, according to the procedure described earlier by Kratz et al. [30] for synovial fluid $\operatorname{IgG}$ and $\mathrm{IgA}$. For lectin-binding analysis only those bands that corresponded to SC detected in immunoblotting with mouse anti-human SC of IgA monoclonal antibodies were taken into consideration (see the section above). Nitrocellulose membranes were labelled with AAL (1:400), LTA (1:200) and UEA (1:200) (Vector Laboratories Inc., Burlingame, CA, USA) diluted in $3 \%$ powdered skim milk in $50 \mathrm{mM}$ TBS $\mathrm{pH}=7.5$, and then detected with alkaline phosphatase-conjugated ExtrAvidin (1:10,000 dilution in $3 \%$ milk in $50 \mathrm{mM}$ TBS $\mathrm{pH}=7.5$; Sigma Chemical Co., St. Louis, MO, USA). The colour reaction was developed with $0.1 \mathrm{M}$ Tris- $\mathrm{HCl} ; 0.1 \mathrm{M} \mathrm{NaCl} ; 0.05 \mathrm{M} \mathrm{MgCl}_{2}, \mathrm{pH}=9.5$ containing $100 \mu \mathrm{l} 7.7 \%$ nitro blue tetrazolium in dimethylformamide (DMF) $(7: 3 ; \mathrm{v} / \mathrm{v})$, and $75 \mu \mathrm{l} 5 \%$ 5-bromo-4chloro-3-indolyl phosphate, disodium salt in DMF. Lastly, the blots were dried and analysed. Bands corresponding to particular AAL-, LTA- and UEA-reactive SC were digitised and analysed with densitometry ImageJ $1.42 \mathrm{q}$ gel analysis software (National Institutes of Health, U.S. Department of Health \& Human Services public domain). The relative amounts of particular fucose-specific SC bands were expressed as the percentage of the total number of pixels in a lane. As described previously, to calculate the molecular masses of SC bands, low molecular-weight protein mass standard (Serva Electrophoresis GmbH, Heidelberg, Germany) and human colostrum S-IgA preparation (Sigma Chemical Co., St. Louis, MO, USA) were used. Specific lectin reactivity reflecting the density of fucosylated epitopes [31, 32] was defined as the ratio of lectin reactivity to the protein content, measured as reactivity with anti-human SC of IgA in a particular band, and calculated as: Lectin reactivity (pixels/band)/ Antibody reactivity (pixels/band). Specific lectin reactivity was used to compare relative fucosylation of both SC forms (Table 2).
Statistical analysis

Statistical analysis was performed using STATISTICA 10.0 software (StatSoft Inc., Tulsa, OK, USA). Experimental data were presented as means and standard deviations (SD), and distribution of the values within analysed groups as box-whisker plots with median and interquartile $\left(25^{\text {th }}-75^{\text {th }}\right.$ percentile) range. According to a Shapiro-Wilk $W$ test, the values did not fit normal distribution, thus the nonparametric Mann-Whitney $U$ test was used to determine differences between groups. Correlations between determined parameters were estimated according to a Spearman test. A two-tailed $p$-value of less than 0.05 was considered significant.

\section{Results}

Concentration of $\operatorname{IgG}$ and secretory $\operatorname{IgA}$

IgG concentration in leukocytospermic seminal plasmas was significantly higher than that observed in normal seminal plasma $(131.7 \pm 103 \mathrm{mg} / \mathrm{l}$ and $67.7 \pm 29 \mathrm{mg} / \mathrm{l}$, respectively; $p<0.02$; Table 1). Also S-IgA concentration was significantly higher in the leukocytospermic group compared to normal seminal plasmas $(36 \pm 27 \mathrm{mg} / \mathrm{l}$ and $19 \pm 18 \mathrm{mg} / \mathrm{l}$, respectively; $p<0.02$; Table 2). The median value of IgG concentration was 104 and $63.3 \mathrm{mg} / 1$, and 28.7 and $9.9 \mathrm{mg} / 1$ for $\mathrm{S}-\operatorname{IgA}$ in leukocytospermic and normal seminal groups, respectively (Fig. 1a, b).

$\operatorname{IgG}$ reactivity with lectins

The relative reactivity of $\operatorname{IgG}$ with AAL was significantly lower in the leukocytospermic seminal group $(0.82 \pm 0.3 \mathrm{AU}$,

Table 1 Relative reactivity of seminal plasma IgG with fucose-specific lectins

\begin{tabular}{lllll}
\hline Group & $\operatorname{IgG}(\mathrm{mg} / \mathrm{l})$ & \multicolumn{2}{l}{$\begin{array}{l}\text { Relative reactivity with lectins } \\
(\mathrm{AU})\end{array}$} & \\
\cline { 3 - 5 } & & $\mathrm{AAL}$ & $\mathrm{UEA}$ & $\mathrm{LTA}$ \\
\hline Normal $(n=17)$ & $67.7 \pm 29$ & $1.2 \pm 0.3$ & $0.42 \pm 0.2$ & $0.35 \pm 0.3$ \\
$\begin{array}{l}\text { Leukocytospermia } \\
(n=28)\end{array}$ & $\begin{array}{l}131.7 \pm 103 \\
p<0.02\end{array}$ & $\begin{array}{l}0.82 \pm 0.3 \\
p<0.002\end{array}$ & $0.34 \pm 0.3$ & $0.51 \pm 0.4$ \\
\hline
\end{tabular}

The concentration of $\mathrm{IgG}$ in seminal plasmas was determined by radial immunodiffusion according to Mancini et al. [22], using goat anti-human IgG polyclonal antibodies. In both seminal plasma groups, the relative reactivity of IgG $(100 \mathrm{ng} / 100 \mu \mathrm{l})$ with fucose-specific lectins was determined by lectin-ELISA [23] using biotinylated lectins AAL, UEA and LTA, and expressed in absorbance units (AU). Results are given as mean value \pm standard deviation. A two-tailed $p$-value of less than 0.05 was considered significant 
Table 2 Relative content of seminal plasma SC reactive with monoclonal antibodies and fucose-specific lectins

\begin{tabular}{|c|c|c|c|c|c|c|c|c|c|}
\hline \multirow[t]{3}{*}{ Group } & \multirow[t]{3}{*}{ S-IgA (mg/l) } & \multicolumn{8}{|c|}{ Relative content of SC $(\%)$} \\
\hline & & \multicolumn{2}{|l|}{ Anti-SC } & \multicolumn{2}{|l|}{ AAL } & \multicolumn{2}{|l|}{ UEA } & \multicolumn{2}{|l|}{ LTA } \\
\hline & & $78 \pm 4.2 \mathrm{kDa}$ & $63 \pm 2.3 \mathrm{kDa}$ & $78 \pm 4.2 \mathrm{kDa}$ & $63 \pm 2.3 \mathrm{kDa}$ & $78 \pm 4.2 \mathrm{kDa}$ & $63 \pm 2.3 \mathrm{kDa}$ & $78 \pm 4.2 \mathrm{kDa}$ & $63 \pm 2.3 \mathrm{kDa}$ \\
\hline \multirow[t]{2}{*}{ Normal $(n=17)$} & \multirow[t]{2}{*}{$19 \pm 18$} & \multirow[t]{2}{*}{83.5} & \multirow[t]{2}{*}{16.5} & 56.8 & 43.2 & 80.4 & 19.6 & 66.3 & 33.7 \\
\hline & & & & $1.9^{\mathrm{a}}$ & $6.9^{\mathrm{a}}$ & $2.9^{\mathrm{a}}$ & $3.4^{\mathrm{a}}$ & $2.1^{\mathrm{a}}$ & $5.1^{\mathrm{a}}$ \\
\hline \multirow{2}{*}{$\begin{array}{l}\text { Leukocytospermia } \\
\qquad(n=28)\end{array}$} & $36 \pm 27$ & \multirow[t]{2}{*}{77.5} & \multirow[t]{2}{*}{22.5} & 66 & 34 & 68.4 & 31.6 & 73.1 & 26.9 \\
\hline & $p<0.02$ & & & $2.3^{\mathrm{a}}$ & $2.7^{\mathrm{a}}$ & $3.6^{\mathrm{a}}$ & $3.8^{\mathrm{a}}$ & $2.6^{\mathrm{a}}$ & $2.2^{\mathrm{a}}$ \\
\hline
\end{tabular}

The concentration of S-IgA in seminal plasmas was determined by immunoenzymatic sandwich ELISA test, using mouse anti-human SC of IgA monoclonal antibodies. Results are given as mean value \pm standard deviation. A two-tailed $p$-value of less than 0.05 was considered significant. Two SC bands were determined by immunoblotting using anti-human SC of IgA monoclonal antibody: $78 \pm 4.2 \mathrm{kDa}$ and $63 \pm 2.3 \mathrm{kDa}$ (see Fig. 4). On the basis of densitometric analysis, the relative content of particular SC bands was expressed as the percentage of the total number of pixels in a lane (for details see Methods section). The reactivity of SC with biotinylated fucose-specific lectins AAL, UEA and LTA was analysed by densitometry as previously described [30]. The relative content of particular fucose-specific SC bands, corresponding to SC bands reactive with anti-human SC of IgA antibodies, was expressed as the percentage of the total number of pixels in a lane

${ }^{a}$ specific lectin reactivity, defined as a ratio of lectin and antibody reactivity (for details see Methods section)

median $0.8 \mathrm{AU} ; p<0.002)$, compared to normal seminal plasmas (1.2 $\pm 0.3 \mathrm{AU}$, median 1.2 AU; Table 1, Fig. 3). Moreover, a negative correlation between $\mathrm{IgG}$ concentration and relative reactivity of $\mathrm{IgG}$ with $\mathrm{AAL}$ was found $(r=-0.52$, $p<0.0003$; Fig. 2a). The relative reactivity of $\operatorname{IgG}$ with UEA was $0.34 \pm 0.3 \mathrm{AU}$ (median $0.3 \mathrm{AU}$ ) and $0.42 \pm 0.2 \mathrm{AU}$ (median $0.4 \mathrm{AU}$; Table 1, Fig. 3) in the leukocytospermic group and normal seminal plasmas, respectively, with no statistical significance of the difference between both seminal groups $(p>0.05)$. However, a negative correlation was observed ( $r=-0.48, p<0.0009$ Fig. $2 b$ ) between IgG concentration and IgG relative reactivity with UEA. Conversely, LTAreactivity of IgG was slightly higher in leukocytospermia $(0.51 \pm 0.4 \mathrm{AU}$, median $0.4 \mathrm{AU})$ than in the normal seminal group ( $0.35 \pm 0.3 \mathrm{AU}$, median $0.2 \mathrm{AU}$; Table 1, Fig. 3), although the difference did not reach statistical significance $(p>0.05)$.

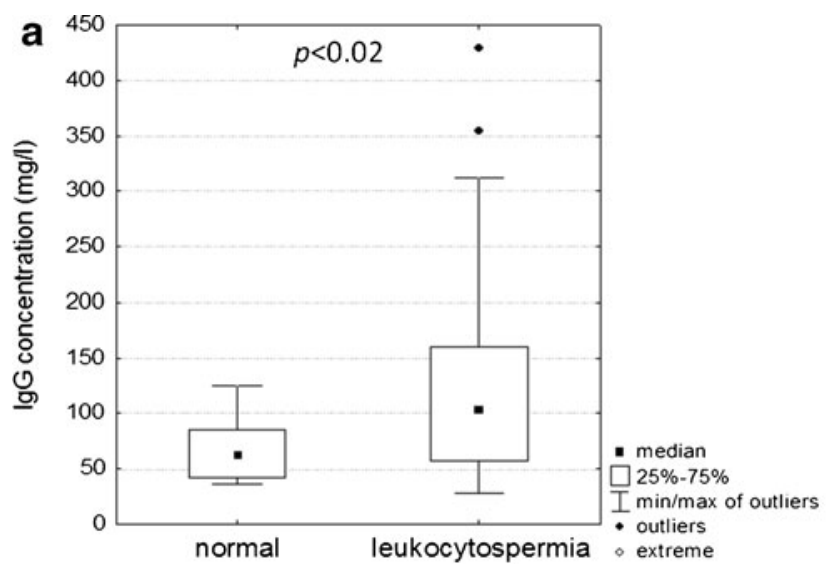

Fig. 1 Concentration of $\operatorname{IgG}$ and S-IgA. The concentrations of $\operatorname{IgG}$ (a) and S-IgA (b) in seminal plasmas were determined by radial immunodiffusion [22] and immunoenzymatic sandwich ELISA test, using goat
$\mathrm{SC}$ reactivity with monoclonal antibody

In the pools of leukocytospermic and normal seminal plasma groups the presence of $78 \pm 4.2-\mathrm{kDa}$ and $63 \pm 2.3-\mathrm{kDa} \mathrm{SC}$ bands were observed in SDS-PAGE under reducing conditions and subsequent immunoblotting with mouse anti-human SC of IgA monoclonal antibody (Fig. 4). Both SC bands may represent free secretory component and/or a fraction of S-IgA (S-IgA1 and/or S-IgA2) released after S-IgA reduction during the SDS-PAGE procedure. Their relative content was different in both seminal groups. The $78-\mathrm{kDa} \mathrm{SC}$ in leukocytospermic seminal plasmas was expressed at $77.5 \%$, and in the normal group at $83.5 \%$, and as a consequence the percentage participation of $63-\mathrm{kDa} \mathrm{SC}$ in the leukocytospermic group was higher $(22.5 \%)$ than in the normal seminal group $(16.5 \%)$ (Table 2).

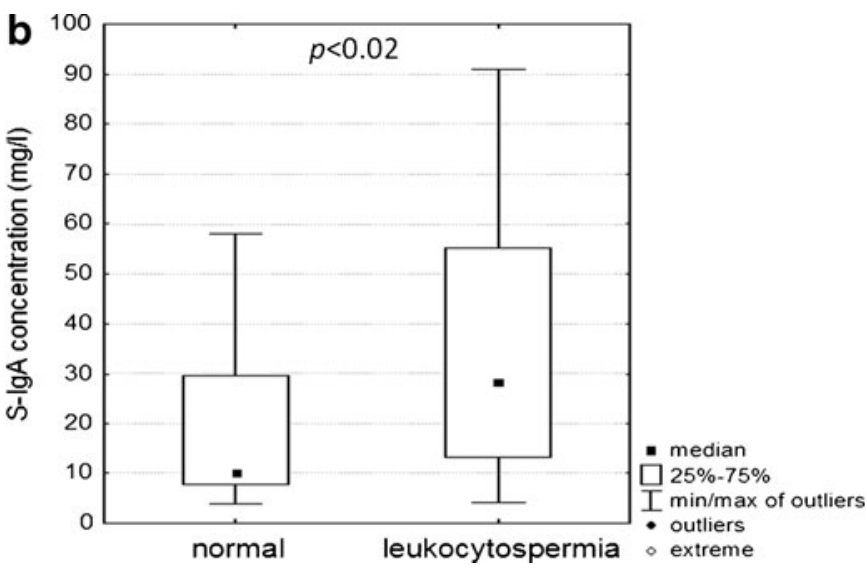

anti-human IgG polyclonal antibodies and mouse anti-human SC of IgA monoclonal antibodies, respectively 


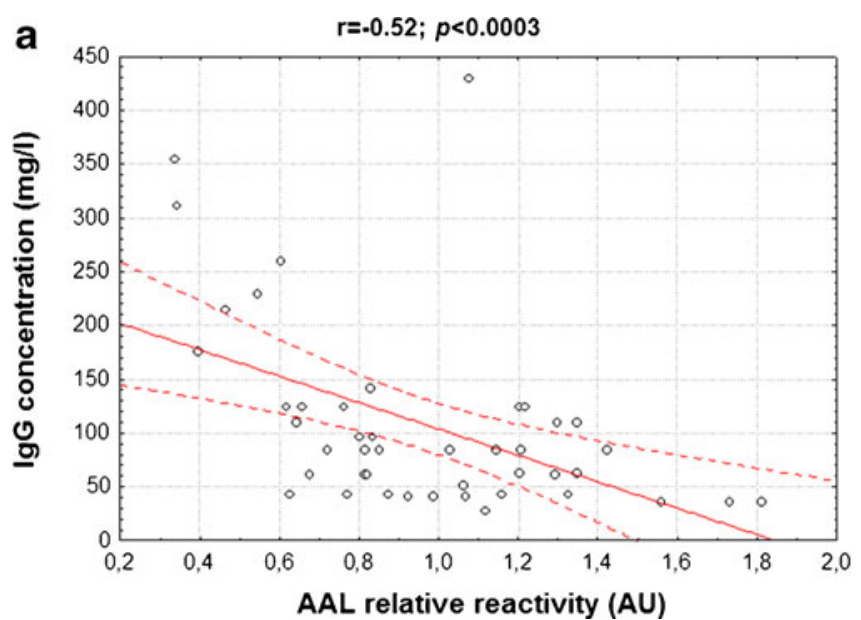

Fig. 2 Dependence between IgG concentration and IgG relative reactivity with lectins. Correlation between $\operatorname{IgG}$ concentration and IgG relative reactivity with AAL (a), and UEA (b) was estimated according to a

$\mathrm{SC}$ reactivity with lectins

The lectin-binding patterns of $\mathrm{SC}$ with fucose-specific lectins are shown in Fig. 5. In the leukocytospermic group, the relative amount of AAL- and LTA-reactive $78-\mathrm{kDa}$ SC bands was visibly higher (66\% and $73.1 \%$, respectively) than those observed for the normal group ( $56.8 \%$ and $66.3 \%$, respectively) (Table 2). The relative amount of UEA-reactive $78-\mathrm{kDa} \mathrm{SC}$ band was lower in the leukocytospermic group in comparison to normal seminal plasma ( $68.4 \%$ and $80.4 \%$, respectively; Table 2).

Despite the fact that $63-\mathrm{kDa}$ fraction accounted for $16.5 \%$ (normal group) and $22.5 \%$ (leukocytospermia) of total SC (Table 2), its contribution in lectin reactivity reached $43 \%$

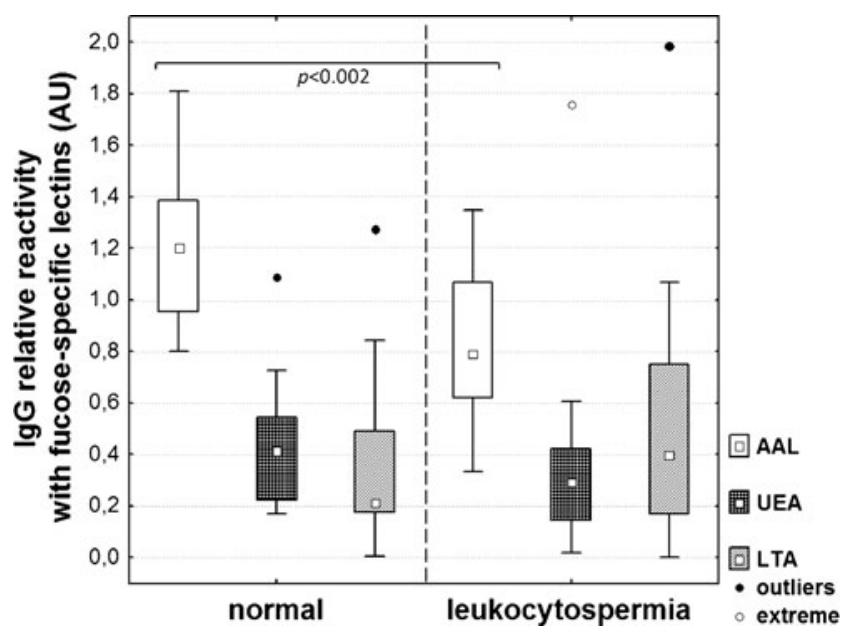

Fig. $3 \mathrm{IgG}$ relative reactivity with fucose-specific lectins. The relative reactivity of seminal $\mathrm{IgG}$ with biotinylated fucose-specific lectins AAL, UEA and LTA was determined in normal and leukocytospermic groups using lectin-ELISA [23] and expressed in absorbance units (AU). $\square-$ median value

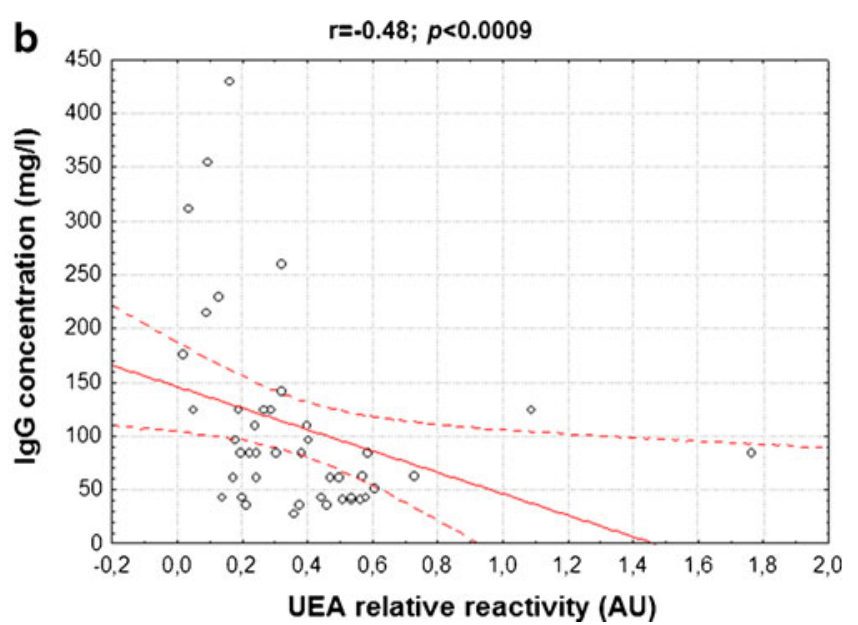

Spearman test, with a two-tailed $p$-value of less than 0.05 considered significant. $95 \%$ confidence interval is marked by dotted lines

(relative amount of AAL-reactive $63-\mathrm{kDa} \mathrm{SC}$ in the normal group) and in all cases was higher than the relative protein content shown in Table 2. This may suggest that fucosylation of low molecular weight $63-\mathrm{kDa} \mathrm{SC}$ was higher than that observed for the 78-kDa fraction. To confirm this suggestion, specific lectin reactivity was calculated, defined as a ratio of lectin reactivity to the protein content in each particular band (see Methods section and Table 2). Specific lectin reactivity of 63-kDa SC with AAL was about 3.6 times higher than that observed for $78-\mathrm{kDa} \mathrm{SC}$ in the normal seminal group (6.9 and 1.9 , respectively), but similar in leukocytospermia (2.7 and

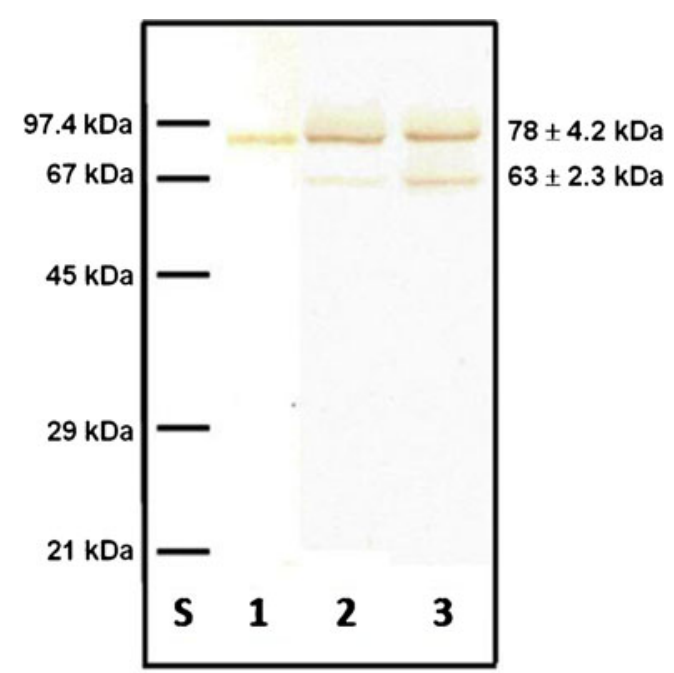

Fig. 4 Representative immunoblotting pattern of seminal SC. $250 \mathrm{ng}$ of S-IgA determined by ELISA (for details see Methods section), was subjected to SDS-PAGE on $10 \%$ gel according to Laemmli [29]. Immunoblots were probed with mouse anti-human SC of IgA monoclonal antibody. Lane $\mathbf{S}$ - low molecular-weight protein mass standard; Lane 1 preparation of S-IgA from human colostrum; Lane $\mathbf{2}$ - normal seminal plasma; Lane $\mathbf{3}$ - leukocytospermic seminal plasma 


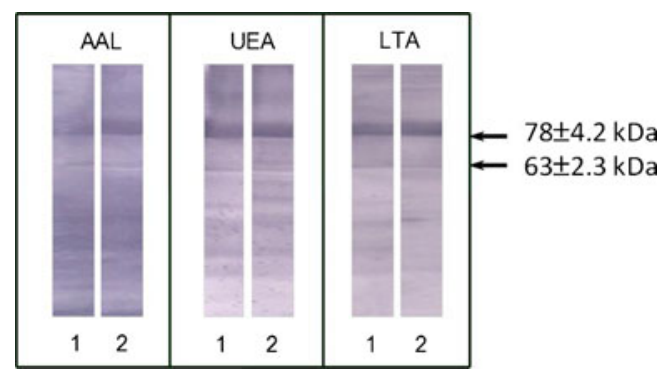

Fig. 5 Relative reactivity of SC with fucose-specific lectins. Lectinblotting with three biotinylated fucose-specific lectins AAL, UEA and LTA [30] was performed for normal (1) and leukocytospermic (2) seminal groups. The bands corresponding to $\mathrm{SC}(78 \pm 4.2 \mathrm{kDa}$ and $63 \pm$ $2.3 \mathrm{kDa}$ ) are shown by arrows

2.3, respectively; Table 2). Also the specific lectin reactivity of $63-\mathrm{kDa} \mathrm{SC}$ with LTA was about 2.5 times higher than that observed for $78-\mathrm{kDa} \mathrm{SC}$ (5.1 and 2.1, respectively) in the normal group. However, no changes between specific lectin reactivity with LTA for both SC bands were observed in leukocytospermia (Table 2). The differences between the specific lectin reactivity with UEA of both $\mathrm{SC}$ forms in the normal and leukocytospermic groups were negligible (Table 2).

\section{Discussion}

Our present work, for the first time, shows the profile and degree of human seminal $\operatorname{IgG}$ and SC fucosylation. The following findings emerge from our studies: (1) in leukocytospermic seminal plasmas, the mean concentrations of IgG and S-IgA are twice as high as in the normal group, (2) the seminal IgG and SC are decorated with core fucose, as well as antennary UEA- and LTA-reactive fucose of Lewis ${ }^{y}$ and Lewis ${ }^{x}$ structures, (3) the IgG present in leukocytospermic samples is characterized by lower expression of AAL-reactive core fucose than in the normal group, (4) in human seminal plasma the SC is present in two forms: $78-\mathrm{kDa}$ and $63-\mathrm{kDa}$, differing in their fucose expression, (5) in the normal seminal group, higher AAL and LTA specific reactivity of $63-\mathrm{kDa} \mathrm{SC}$ glycans is observed as opposed to $78-$ $\mathrm{kDa} \mathrm{SC}$, (6) in leukocytospermia the values of specific lectin reactivity for core and Lewis ${ }^{\mathrm{x}}$ fucose of $63-\mathrm{kDa} \mathrm{SC}$ were lower but similar for both SC forms.

In all the glycosylation studies based on the application of lectins, the results shouldn't be regarded as reflecting the accurate structure of the oligosaccharides. Lectins may be able to bind less preferred structures when they are abundant enough, but also not bind the glycans which are conformationally hidden in the glycoprotein structure. In spite of this drawback, lectin reactivity reflects the real accessibility of the analysed glycoepitopes in the native microenvironment, thus also their potential for interactions in vivo.

It is suggested that the content of L-fucose in the glycan moiety of seminal plasma glycoproteins, as well as fucose location in these structures, may influence various interactions during sperm maturation and fertilization cascade. Seminal plasma oligosaccharides containing fucose of Lewis ${ }^{\mathrm{x}}$ and/or Lewis ${ }^{y}$ glycotopes, both as free oligosaccharides and attached to glycoconjugates, participate in sperm-egg binding initiating the fertilization process [33], and has been reported to interfere with gamete fusion [34]. Fucosylation of immunoglobulins may be of key importance due to their participation in the immune response.

Concentrations of seminal IgG determined in the normal group (Table 1) corresponded to the values reported earlier $[35,36]$. The slightly higher S-IgA concentrations previously reported [21] may result from different characteristics of normozoospermic groups. In the previous study, normozoospermic semen samples were collected from men living in infertile couples, while the group analysed here is composed of apparently fertile men. In leukocytospermic seminal plasma, the concentration of both IgG and S-IgA was significantly increased, and this may be due to inflammation of the male reproductive organs of various aetiology. The presence of antisperm IgG antibodies may be also possible. High immunoglobulin level and increased defence reactions may, however, be harmful for fertility potential. For example the speed of sperm penetration through the cervical mucus and fertilization effectiveness were reduced when at least $50 \%$ of motile sperm were bound to $\operatorname{IgG}$ antibodies [37].

Changes in $\alpha(1-6)$ core fucosylation of IgG glycans are associated with the effector functions of immunoglobulin $G$ $[12,13]$. Lack of the core fucose on IgG glycans, resulting from the decreased activity of $\alpha 1,6$-fucosyltransferase [38], or the presence of bisecting GlcNAc [39], may contribute to defence mechanisms [35], through increased cytotoxicity of NK cells and monocytes [40]. The changes in the expression of immunoglobulin $\mathrm{G}$ core fucosylation were observed in some diseases including rheumatoid arthritis [30, 41, 42] and different types of cancer: ovarian [43], stomach [44] and liver [45]. Core fucose is also known to protect $\mathrm{N}$-glycans via inhibition of their hydrolysis with glycoasparaginases [46]. On the other hand, fucose located in the antennary part of glycans of Lewis ${ }^{y}$ and Lewis ${ }^{\mathrm{x}}$-/sialyl-Lewis ${ }^{\mathrm{x}}$ antigens is known to participate in cellular recognition. Antennary fucose of Lewis ${ }^{\mathrm{x}}$ and Lewis ${ }^{\mathrm{y}}$ types may be engaged in binding and inactivation of bacteria through interaction with bacterial adhesins [17]. The sperm surface was shown to contain numerous receptors for simple and complex sugars [47-51]. Incubation of the male gametes with fucoidin inhibits the binding of sperm to the zona pellucida of the oocyte $[52,53]$. Therefore, antennary fucose $\alpha(1-2)$ - linked, present in glycans of seminal plasma glycoproteins [54], and bifucosylated Lewis ${ }^{\mathrm{y}}$ oligosaccharide structures can participate in adhesion in the maternal-fetal interactions during embryo implantation $[55,56]$.

In our study we have found a significant decrease of $\operatorname{IgG}$ AAL-reactivity and a negative correlation of this core fucose 
expression with $\operatorname{IgG}$ concentration in seminal plasma. This may elevate effector interactions of $\mathrm{IgG}$ and cytotoxicity of NK in leukocytospermic patients, which may also result in some damage of sperm cells. The differences in IgG UEA- and LTA-reactivity between normal and leukocytospermic groups are slight and statistically insignificant. However, comparing the reactivity of seminal plasma $\operatorname{IgG}$ with all three fucosespecific lectins, it is noteworthy that in leukocytospermic IgG there is a shift in fucose location from the core to antennary part, making an increase in Lewis ${ }^{\mathrm{x}}$ possible. Termination of glycans with sialic acid is known to limit binding of LTA [27]. Recently, similar observations were also made for core-fucose specific AAL $[57,58]$. On the other hand, the presence of $\alpha(2-3)$ - linked sialic acid prevents formation of bifucosylated, UEA-reactive Lewis $^{\mathrm{y}}$ antigens [26]. In IgG, the accessibility of fucose may also be influenced by conformational changes hiding the glycans inside an $\mathrm{Fc}$ structure [58]. Thus, the results presented here reflect the accessibility of glycans for the ligands differing in their specificity. To obtain more information on the real chemical structure of the oligosaccharides, further sialylation and structural studies are planned.

Secretory component of IgA is capable of reacting via its glycans with bacterial adhesins leading to inactivation and prevention of infection by bacterial microorganisms [59]. In human secretions, $\mathrm{SC}$ is reported to exist in both free and $\operatorname{IgA}$ bound forms. It is not clear, however, if there is any difference in their structure and function $[14,60]$. In seminal plasma, as well as in human colostrum, two forms of secretory component were found, differing in their molecular masses. The values are reported as $80-90 \mathrm{kDa}$ for the bigger, and 50 $65 \mathrm{kDa}$ for the smaller form [14, 21, 60]. In the present study molecular masses determined in the immunoblotting analysis of seminal plasma with specific anti-human SC of IgA monoclonal antibody, were $78 \pm 4.2 \mathrm{kDa}$ and $63 \pm 2.3 \mathrm{kDa}$ (Table 2; Fig. 4). The origin or structural difference between these two forms is still not clear. Almogren et al. [60] have suggested that the $62-\mathrm{kDa} \mathrm{SC}$ is a deglycosylated form of $80-\mathrm{kDa} \mathrm{SC}$. Although different glycosylation profiles of the two seminal SC bands observed by us are possible, both of them were capable of binding lectins, thus contain glycan moiety. The smaller form may also result from partial degradation of the 78-kDa SC form [60]. It also cannot be excluded that both fractions represent free secretory component and a fraction bound to IgA as part of S-IgA (S-IgA1 and/or S-IgA2) present in native seminal plasma and released after S-IgA reduction during the procedure of SDS-PAGE.

Comparison of the relative content of both fractions in normal and leukocytospermic seminal plasmas indicates increased expression of $63-\mathrm{kDa} \mathrm{SC}$ associated with leukocytospermia ( $22.5 \%$ for the leukocytospermic and $16.5 \%$ for the normal group; Table 2). If partial deglycosylation or degradation is the mechanism of the formation of the $63-\mathrm{kDa} \mathrm{SC}$ form, its increased content may cause the debilitation of its biological antibacterial function. This in turn may reduce the ability of SC to defend sperm against infection and thus influence fertility. SC is reported to contain as many as 5-7 N-linked oligosaccharides of different structures, containing Lewis ${ }^{\mathrm{a}}$, Lewis ${ }^{\mathrm{x}}$ and Lewis ${ }^{\mathrm{y}}$ structures. The main role of glycans is to protect the SC and S-IgA against proteases, but the glycans are also responsible for the binding of lectins and bacterial adhesins [17]. Alterations in the glycosylation profile probably influence the biological functions of S-IgA and SC as well [17].

Fucosylation of SC was examined by means of lectinblotting, which, as opposed to ELISA tests, enables comparison of reactivity with fucose-specific lectins for both SC forms. Our experiments indicate that the relative reactivity of both SC fractions with the three fucose-specific lectins differ between the normal and leukocytospermic groups. The relative content of the lectin-reactive 63-kDa SC form (19.6$43.2 \%$ ) for all three lectins in both groups exceeds its protein content (16.5-22.5\%). It could be hypothesised that fucose expression in the glycans of the $63-\mathrm{kDa}$ form is stronger than in $78-\mathrm{kDa}$ SC. To evaluate this hypothesis, specific lectin reactivity was estimated, defined as a ratio of lectin reactivity to protein content in both forms (Table 2, values with a). Such an attempt enables comparison of the fucose content extrapolated to the protein amount and reflects the density of fucosylated epitopes on the protein surface [31, 32]. In the group with normal semen, the density of AAL-reactive fucosylated epitopes was 3.5-times higher in $63-\mathrm{kDa}$ than in the $78-\mathrm{kDa}$ fraction. Similarly, the density of LTA-reactive fucose was 2.5-times higher in the smaller SC form. In leukocytospermia, the values were comparable for all three lectins. Also the density of the recognized epitopes was similar for all three lectins and both groups in the $78-\mathrm{kDa} \mathrm{SC}$ form. The leukocytospermic $63-\mathrm{kDa} \mathrm{SC}$ form thus appears to express lower density LTA- and AAL-reactive fucose corresponding to Lewis ${ }^{\mathrm{x}}$ antigen and core fucose. This may result in the altered ability of the $63-\mathrm{kDa} \mathrm{SC}$ form to interact with bacteria and disturb its defence function. Further examination of the origin and structural difference of the two forms of secretory component as well as their glycosylation are demanded to explain if such changes may be important for the defence molecular mechanism.

In conclusion, the analysis of IgG and SC fucosylation in seminal plasma is an indicator for some disease-related alterations. If an analysis of the sensitivity and specificity of changes reported here will also be satisfactory, these glycosylation traits might constitute valuable diagnostic tools for the evaluation of infertility with accompanying leukocytospermia. Additionally, such information may be helpful as a parameter for selecting the appropriate assisted reproduction technique to be used in leukocytospermic patients. However, larger studies are needed to explore the role of seminal $\operatorname{IgG}$ and $\mathrm{SC}$ fucosylation profiles in male fertility. Moreover, the fucosylation of seminal IgA molecules might also be interesting, especially 
in the context of male fertility. Our study did not show the exact glycan structures, but reflects the exposition of the conformationally accessible fucose of seminal $\mathrm{IgG}$ and SC for external and internal ligands. Further studies focused on the explanation of the origin and structural differences between two SC forms present in seminal plasma are required because the different fucose expression may be of significant importance for the appropriate function of both free and bound SC forms. Our results suggest that the decrease of both core and Lewis ${ }^{\mathrm{x}}$ type fucose content in the $63-\mathrm{kDa} \mathrm{SC}$ form in leukocytospermic seminal plasmas may influence the effectiveness of $\mathrm{SC}$ in its defence against internal infections of the male reproductive tract.

Acknowledgments This work was supported by the Medical Faculty (No ST-562), Wrocław Medical University (Poland). The authors thank Dr. Felix Toka from the Warsaw Agricultural University (Poland) for comments and critical reading of the manuscript.

Open Access This article is distributed under the terms of the Creative Commons Attribution License which permits any use, distribution, and reproduction in any medium, provided the original author(s) and the source are credited.

\section{References}

1. World Health Organization: WHO laboratory manual for the examination and processing of human semen. WHO Press, 20 Avenue Appia, 1211 Geneva 27, Switzerland (2010)

2. Kiessling, A.A., Lamparelli, N., Yin, H.Z., Seibel, M.M., Eyre, R.C.: Semen leukocytes: friends or foes? Fertil. Steril. 64, 196-198 (1995)

3. Kaleli, S., Oçer, F., Irez, T., Budak, E., Aksu, M.F.: Does leukocytospermia associate with poor semen parameters and sperm functions in male infertility? The role of different seminal leukocyte concentrations. Eur. J. Obstet. Gynecol. Reprod. Biol. 89, 185-191 (2000)

4. Comhaire, F., Verschraegen, G., Vermeulen, L.: Diagnosis of accessory gland infection and its possible role in male infertility. Int. J. Androl. 3, 32-45 (1980)

5. Henkel, R., Maass, G., Hajimohammad, M., Menkveld, R., Stalf, T., Villegas, J., Sánchez, R., Kruger, T.F., Schill, W.B.: Urogenital inflammation: changes of leukocytes and ROS. Andrologia 35, 309-313 (2003)

6. Aitken, R.J., Baker, H.W.: Seminal leukocytes: passengers, terrorists or good samaritans? Hum. Reprod. 10, 1736-1739 (1995)

7. Sharma, R.K., Pasqualalotto, A.E., Nelson, D.R., Thomas Jr., A.J., Agarwal, A.: Relationship between seminal white blood cell counts and oxidative stress in men treated at an infertility clinic. J. Androl. 22, 575-583 (2001)

8. Punab, M., Lõivukene, K., Kermes, K., Mändar, R.: The limit of leucocytospermia from the microbiological viewpoint. Andrologia 35, 271-278 (2003)

9. Yilmaz, S., Koyuturk, M., Kilic, G., Alpak, O., Aytoz, A.: Effects of leukocytospermia on semen parameters and outcomes of intracytoplasmic sperm injection. Int. J. Androl. 28, 337-342 (2005)

10. Routier, F.H., Hounsell, E.F., Rudd, P.M., Takahashi, N., Bond, A., Hay, F.C., Alavi, A., Axford, J.S., Jefferis, R.: Quantitation of the oligosaccharides of human serum IgG from patients with rheumatoid arthritis: a critical evaluation of different methods. J. Immunol. Methods 213, 113-130 (1998)
11. Wada, Y., Azadi, P., Costello, C.E., Dell, A., Dwek, R.A., Geyer, H., Geyer, R., Kakehi, K., Karlsson, N.G., Kato, K., Kawasaki, N., Khoo, K.H., Kim, S., Kondo, A., Lattova, E., Mechref, Y., Miyoshi, E., Nakamura, K., Narimatsu, H., Novotny, M.V., Packer, N.H., Perreault, H., Peter-Katalinic, J., Pohlentz, G., Reinhold, V.N., Rudd, P.M., Suzuki, A., Taniguchi, N.: Comparison of the methods for profiling glycoprotein glycans-HUPO Human Disease Glycomics/Proteome Initiative multi-institutional study. Glycobiology 17, 411-422 (2007)

12. Shields, R.L., Lai, J., Keck, R., O’Connell, L.Y., Hong, K., Meng, Y.G., Weikert, S.H., Presta, L.G.: Lack of fucose on human IgG1 Nlinked oligosaccharide improves binding to human Fcgamma RIII and antibody-dependent cellular toxicity. J. Biol. Chem. 277, 2673326740 (2002)

13. Huhn, C., Selman, M.H., Ruhaak, L.R., Deelder, A.M., Wuhrer, M.: IgG glycosylation analysis. Proteomics 9, 882-913 (2009)

14. Norderhaug, I.N., Johannes, F.E., Schijerven, H., Brandtzaeg, P.: Regulation of the formation and external transport of secretory immunoglobulins. Crit. Rev. Immunol. 19, 481-508 (1999)

15. Woof, J.M., Kerr, M.A.: The function of immunoglobulin A in immunity. J. Pathol. 208, 270-282 (2006)

16. Dickinson, E.C., Gorga, J.C., Garrett, M., Tuncer, R., Boyle, P., Watkins, S.C., Alber, S.M., Parizhskaya, M., Trucco, M., Rowe, M.I., Ford, H.R.: Immunoglobulin A supplementation abrogates bacterial translocation and preserves the architecture of the intestinal epithelium. Surgery 124, 284-290 (1998)

17. Royle, L., Roos, A., Harvey, D.J., Wormald, M.R., van GijlswijkJanssen, D., Redwan, e.-R.M., Wilson, I.A., Daha, M.R., Dwek, R.A., Rudd, P.M.: Secretory IgA N- and O-glycans provide a link between the innate and adaptive immune systems. J. Biol. Chem. 278, 20140-20153 (2003)

18. Kaetzel, C.S., Mostov, K.: Immunoglobulin transport and the polymeric immunoglobulin receptor. In: Mestecky, J., Bienenstock, J., Lamm, M.E., Mayer, L., McGhee, J.R., Strober, W. (eds.) Mucosal Immunology, pp. 211-250. Elsevier/Academic Press, Amsterdam (2005)

19. Crottet, P., Corthésy, B.: Secretory component delays the conversion of secretory $\operatorname{IgA}$ antigen-binding component $\mathrm{F}(\mathrm{ab}$ ')2: a possible implication for muscosal defence. J. Immunol. 161, 5445-5453 (1998)

20. Woof, J.M., Mestecky, J.: Mucosal immunoglobulins. Immunol. Rev. 206, 64-82 (2005)

21. Kratz, E.M., Pupek, M., Chełmońska-Soyta, A., Kątnik-Prastowska, I.: The molecular forms of immunoglobulin $\mathrm{A}$ in human seminal plasma. Adv. Clin. Exp. Med. 13, 541-547 (2004)

22. Mancini, G., Carbonara, A.O., Heremans, J.F.: Immunochemical quantitation of antigens by single radial immunodiffusion. Immunochemistry 2, 235-254 (1965)

23. Kratz, E.M., Faundez, R., Katnik-Prastowska, I.: Fucose and sialic acid expressions in human seminal fibronectin and $\alpha_{1}$-acid glycoprotein associated with leukocytospermia of infertile men. Dis. Markers 31, 317-325 (2011)

24. Yamashita, K., Kochibe, N., Ohkura, T., Ueda, I., Kobata, A.: Fractionation of L-fucose-containing oligosaccharides on immobilized Aleuria aurantia lectin. J. Biol. Chem. 260, 4688-4693 (1985)

25. Loris, R., De Greve, H., Dao-Thi, M.H., Messens, J., Imberty, A., Wyns, L.: Structural basis of carbohydrate recognition by lectin II from Ulex europaeus, a protein with a promiscuous carbohydratebinding site. J. Mol. Biol. 301, 987-1002 (2000)

26. Zerfaoui, M., Fukuda, M., Sbarra, V., Lombardo, D., El-Battari, A.: Alpha(1,2)-fucosylation prevents sialyl Lewis $\mathrm{x}$ expression and Eselectin-mediated adhesion of fucosyltransferase VII-transfected cells. Eur. J. Biochem. 267, 53-61 (2000)

27. Yan, L., Wilkins, P.P., Alvarez-Manilla, G., Do, S.I., Smith, D.F., Cummings, R.D.: Immobilized Lotus tetragonolobus agglutinin binds oligosaccharides containing the Le(x) determinant. Glycoconj. J. 14, 45-55 (1997) 
28. Kątnik, I., Jadach, J., Krotkiewski, H., Gerber, J.: Investigating the glycosylation of normal and ovarian cancer haptoglobins using digoxigenin-labeled lectins. Glycosyl. Dis. 1, 97-104 (1994)

29. Laemmli, U.K.: Cleavage of structural proteins during the assembly of the fead of bacteriophage T4. Nature 227, 680-685 (1970)

30. Kratz, E.M., Borysewicz, K., Katnik-Prastowska, I.: Terminal monosaccharide screening of synovial immunoglobulins $\mathrm{G}$ and $\mathrm{A}$ for the early detection of rheumatoid arthritis. Rheumatol. Int. 30, 1285$1292(2010)$

31. Kossowska, B., Ferens-Sieczkowska, M., Gancarz, R., PassowiczMuszyńska, E., Jankowska, R.: Fucosylation of serum glycoproteins in lung cancer patients. Clin. Chem. Lab. Med. 43, 361-369 (2005)

32. Ferens-Sieczkowska, M., Kossowska, B., Gancarz, R., Dudzik, D., Knas, M., Popko, J., Zwierz, K.: Fucosylation in synovial fluid as a novel clinical marker for differentiating joint diseases-a preliminary study. Clin. Exp. Rheumatol. 25, 92-95 (2007)

33. Chalabi, S., Easton, R.L., Patankar, M.S., Lattanzio, F.A., Morrison, J.C., Panico, M., Morris, H.R., Dell, A., Clark, G.F.: The expression of free oligosaccharides in human seminal plasma. J. Biol. Chem. 277, 32562-32570 (2002)

34. Nakano, M., Yonezawa, N.: Localization of sperm ligand carbohydrate chains in pig zona pellucida glycoproteins. Cells Tissues Organs 168, 65-75 (2001)

35. Fowler Jr., J.E., Mariano, M.: Immunoglobulin in seminal fluid of fertile, infertile, vasectomy and vasectomy reversal patients. J. Urol. 129, 869-872 (1983)

36. Luckas, M.J.M., Buckett, W.M., Aird, I.A., Johnson, P.M., LewisJones, D.I.: Seminal plasma immunoglobulin concentrations in autoimmune male subfertility. J. Reprod. Immunol. 37, 171-180 (1998)

37. Abshagen, K., Behre, H.M., Cooper, T.G., Nieschlag, E.: Influence of sperm surface antibodies on spontaneous pregnancy rates. Fertil. Steril. 70, 355-356 (1998)

38. Imai-Nishiya, H., Mori, K., Inoue, M., Wakitani, M., Iida, S., Shitara, K., Satoh, M.: Double knockdown of alpha1,6-fucosyltransferase (FUT8) and GDP-mannose 4,6-dehydratase (GMD) in antibodyproducing cells: a new strategy for generating fully non-fucosylated therapeutic antibodies with enhanced ADCC. BMC Biotechnol. 7, 84 (2007)

39. Ferrara, C., Brünker, P., Suter, T., Moser, S., Püntener, U., Umaña, P.: Modulation of therapeutic antibody effector functions by glycosylation engineering: influence of Golgi enzyme localization domain and coexpression of heterologous beta1, 4-N-acetylglucosaminyltransferase III and Golgi alpha-mannosidase II. Biotechnol. Bioeng. 93, 851-861 (2006)

40. Forero, A., Lobuglio, A.F.: History of antibody therapy for nonHodgkin's lymphoma. Semin. Oncol. 30, 1-5 (2003)

41. Gornik, I., Maravić, G., Dumić, J., Flögel, M., Lauc, G.: Fucosylation of $\operatorname{IgG}$ heavy chains is increased in rheumatoid arthritis. Clin. Biochem. 32, 605-608 (1999)

42. Alavi, A., Axford, J.S.: Sweet and sour: the impact of sugars on disease. Rheumatology (Oxford) 47, 760-770 (2008)

43. Alley Jr., W.R., Vasseur, J.A., Goetz, J.A., Svoboda, M., Mann, B.F., Matei, D.E., Menning, N., Hussein, A., Mechref, Y., Novotny, M.V.: $\mathrm{N}$-linked glycan structures and their expressions change in the blood sera of ovarian cancer patients. J. Proteome Res. 11, 2282-2300 (2012)

44. Kodar, K., Izotova, J., Klaamas, K., Sergeyev, B., Järvekülg, L., Kurtenkov, O.: Aberrant glycosylation of the anti-ThomsenFriedenreich glycotope immunoglobulin $\mathrm{G}$ in gastric cancer patients. World J. Gastroenterol. 19, 3573-3582 (2013)
45. Comunale, M.A., Wang, M., Hafner, J., Krakover, J., Rodemich, L., Kopenhaver, B., Long, R.E., Junaidi, O., Bisceglie, A.M., Block, T.M., Mehta, A.S.: Identification and development of fucosylated glycoproteins as biomarkers of primary hepatocellular carcinoma. J. Proteome Res. 8, 595-602 (2009)

46. Becker, D.J., Lowe, J.B.: Fucose: biosynthesis and biological function in mammals. Glycobiology 13, 41R-53R (2003)

47. Oehninger, S., Clark, G.F., Acosta, A.A., Hodgen, G.D.: Nature of the inhibitory effect of complex saccharide moieties on the tight binding of human spermatozoa to the human zona pellucida. Fertil. Steril. 55, 165-169 (1991)

48. Mori, K., Daitoh, T., Kamada, M., Maeda, N., Maegawa, M., Hirano, K., Irahara, M., Aono, T.: Blocking of human fertilization by carbohydrates. Hum. Reprod. 8, 1729-1732 (1993)

49. Brandelli, A., Miranda, P.V., Tezon, J.G.: Participation of glycosylated residues in the human sperm acrosome reaction: possible role of N-acetylglucosaminidase. Biochim. Biophys. Acta 1220, 299-304 (1994)

50. Lucas, H., Bercegeay, S., Le Pendu, J., Jean, M., Mirallie, S., Barriere, P.: A fucose-containing epitope potentially involved in gamete interaction on the human zona pellucida. Hum. Reprod. 9, 1532-1538 (1994)

51. Maymon, B.B., Maymon, R., Ben-Nun, I., Ghetler, Y., Shalgi, R., Skutelsky, E.: Distribution of carbohydrates in the zona pellucida of human oocytes. J. Reprod. Fertil. 102, 81-86 (1994)

52. Huang, T.T.F., Ohzu, E., Yanagimachi, R.: Evidence suggesting that L-fucose is part of the recognition signal for sperm-zona pellucida attachment in mammals. Gamete Res. 5, 355-361 (1982)

53. Pang, P.C., Chiu, P.C., Lee, C.L., Chang, L.Y., Panico, M., Morris, H.R., Haslam, S.M., Khoo, K.H., Clark, G.F., Yeung, W.S., Dell, A.: Human sperm binding is mediated by the sialyl-Lewis(x) oligosaccharide on the zona pellucida. Science 333, 1761-1764 (2011)

54. Pang, P.C., Tissot, B., Drobnis, E.Z., Morris, H.R., Dell, A., Clark, G.F.: Analysis of the human seminal plasma glycome reveals the presence of immunomodulatory carbohydrate functional groups. J. Proteome Res. 8, 4906-4915 (2009)

55. Ge, C.H., Kong, Y., Wang, H., Zhu, Z.M.: Effects of blastocyst surface ligosaccharide LeY on secretion and expression of matrix metalloproteinase in vivo. Sheng Wu Hua Xue Yu Sheng Wu Wu Li Xue Bao (Shanghai) 34, 45-49 (2002)

56. Li, Y., Ma, K., Sun, P., Liu, S., Qin, H., Zhu, Z., Wang, X., Yan, Q.: LeY oligosaccharide upregulates DAG/PKC signaling pathway in the human endometrial cells. Mol. Cel. Biochem. 331, 1-7 (2009)

57. Mehta, A.S., Long, R.E., Comunale, M.A., Wang, M., Rodemich, L., Krakover, J., Philip, R., Marrero, J.A., Dwek, R.A., Block, T.M.: Increased levels of galactose-deficient anti-Gal immunoglobulin $\mathrm{G}$ in the sera of hepatitis $\mathrm{C}$ virus-infected individuals with fibrosis and cirrhosis. J. Virol. 82, 1259-1270 (2008)

58. Chen, S., Lu, C., Gu, H., Mehta, A., Li, J., Romano, P.B., Horn, D., Hooper, D.C., Bazemore-Walker, C.R., Block, T.: Aleuria Aurantia Lectin (AAL)-reactive immunoglobulin G rapidly appears in sera of animals following antigen exposure. PLoS One 7 , e44422 (2012)

59. Dallas, S.D., Rolfe, R.D.: Binding of Clostridium difficile toxin A to human milk secretory component. J. Med. Microbiol. 47, 879-888 (1998)

60. Almogren, A., Bonner, A., Perkins, S.J., Kerr, M.A.: Functional and structural characterisation of human colostrum free secretory component. Mol. Immunol. 46, 1534-1541 (2009) 